Bariatric Surgery

\title{
The curious fate of bone following bariatric surgery: bone effects of sleeve gastrectomy (SG) and Roux-en- $Y$ gastric bypass (RYGB) in mice
}

\author{
Katrien Corbeels $\mathbb{D D}^{1} \cdot$ Lieve Verlinden $^{1} \cdot$ Matthias Lannoo $^{1,2} \cdot$ Rougin Khalil $^{1} \cdot$ Ellen Deleus $^{2} \cdot$ Ann $^{\text {Mertens }} \mathbb{D D}^{1,3} \cdot$ \\ Christophe Matthys $^{1,3} \cdot$ Annemieke Verstuyf $^{1} \cdot$ Ann Meulemans $^{1,3} \cdot$ Roman Vangoitsenhoven $^{1,3} \cdot$ Geert Carmeliet $^{1}$. \\ Bart Van der Schueren ${ }^{1,3}$
}

Received: 21 November 2019 / Revised: 12 May 2020 / Accepted: 1 June 2020

(c) The Author(s), under exclusive licence to Springer Nature Limited 2020

\begin{abstract}
Background Bone loss and increased fracture risk following bariatric surgery has been reported. We investigated whether the two most commonly performed surgeries, sleeve gastrectomy (SG) and Roux-en-Y gastric bypass (RYGB), lead to bone loss. In addition, we examined whether fortification of the diet with calcium citrate prevents bone loss.

Methods We used mouse models for SG and RYGB and compared bone loss with a group of sham mice with similar weight loss. All groups were switched at the time of surgery to a low-fat diet (LFD). We also examined whether fortification of the diet with calcium citrate and vitamin $\mathrm{D}$ was able to prevent bone loss.

Results At 2 weeks we observed no major bone effects. However, at 8 weeks, both trabecular and cortical bone were lost to the same extent after SG and RYGB, despite increased calcium absorption and adequate serum levels of calcium, vitamin D, and parathyroid hormone (PTH). Diet fortification with calcium citrate and vitamin D was able to partially prevent bone loss. Conclusions Both SG and RYGB lead to excess bone loss, despite intestinal adaptations to increase calcium absorption. Fortifying the diet with calcium citrate and vitamin D partly prevented the observed bone loss. This finding emphasizes the importance of nutritional support strategies after bariatric surgery, but also affirms that the exact mechanisms leading to bone loss after bariatric surgery remain elusive and thus warrant further research.
\end{abstract}

\section{Introduction}

As a result of the worldwide obesity epidemic, the number of surgeries aimed at achieving sustained weight loss with reversal or even remission of obesity associated

Supplementary information The online version of this article (https:// doi.org/10.1038/s41366-020-0626-3) contains supplementary material, which is available to authorized users.

Katrien Corbeels

katrien.corbeels@kuleuven.be

1 Clinical and Experimental Endocrinology, Department of Chronic Diseases, Metabolism and Ageing (CHROMETA), KU Leuven, Leuven, Belgium

2 Department of Abdominal Surgery, University Hospitals Leuven, Leuven, Belgium

3 Department of Endocrinology, University Hospitals Leuven, Leuven, Belgium comorbidities has surged over the last decades [1]. The benefits of the most commonly performed types of surgeries, i.e. sleeve gastrectomy (SG) and Roux-en-Y gastric bypass (RYGB), are widely recognized, but recent reports of decreased bone mineral density (BMD) and increased fracture risk following surgery have raised concerns [2-6]. A higher incidence of bone fractures may inflate healthcare costs and lead to decreased quality of life and even excess mortality as the patient population that underwent bariatric surgery ages. Thus, an effective strategy to prevent the postsurgical bone loss is eagerly awaited, but requires a good understanding of the underlying mechanisms. The bone loss observed after bariatric surgery has been predominately attributed to a decreased uptake of calcium and vitamin D from the gut. When serum calcium levels drop as a result of calcium malabsorption, parathyroid hormone (PTH) levels rise, causing efflux of calcium from the bones and increased reabsorption in the kidney, in an attempt to restore serum calcium. In addition, PTH increases the conversion of inactive vitamin D $(25(\mathrm{OH}) \mathrm{D})$ to active 
vitamin $\mathrm{D}\left(1,25(\mathrm{OH})_{2} \mathrm{D}\right)$ which enhances intestinal calcium absorption and stimulates calcium and phosphate reabsorption in the kidney [7]. However, as the duodenum is bypassed after RYGB, this compensatory increase in intestinal absorption might be hampered, leading to further calcium efflux from the bones as the secondary hyperparathyroidism (SHPT) settles in.

While calcium malabsorption seems a plausible explanation for bone loss after RYGB, recent studies suggest similar bone effects after SG despite the preserved intestinal anatomy. This observation raises doubts on whether calcium malabsorption is the cause that explains bone loss after surgery [8-16]. In addition, a number of studies have reported a decrease in BMD following weight loss surgery despite normal PTH levels, further discrediting calcium malabsorption as prime factor responsible for bone loss [10, 17-20]. However, it remains unclear which other mechanisms are involved.

Therefore, we developed mouse models for SG and RYGB to map bone status and calcium homeostasis. This approach allows us to compare the effects of SG and RYGB on calcium and vitamin D handling and bone. In addition, we set out to examine whether diets fortified in calcium alone or calcium and vitamin $\mathrm{D}$ are able to prevent bone loss. The latter supports the current recommendation for fortification with calcium and vitamin $\mathrm{D}$ as outlined in the clinical guidelines for post-bariatric care [21, 22].

\section{Materials and methods}

\section{Animals and interventions}

Eight-week-old male C57BL/6 mice (Charles River, Brussels, Belgium) were fed a high-fat diet (HFD) (D12492, Research Diets, New Jersey, USA, containing $0.9 \%$ calcium and $1500 \mathrm{IU} / \mathrm{kg}$ vit $\mathrm{D}_{3}, 60 \% \mathrm{kcal}$ fat, $5.21 \mathrm{kcal} / \mathrm{g}$ ) for 14 weeks to achieve diet-induced obesity (DIO). They were housed in a $12 / 12 \mathrm{~h} \mathrm{light/dark} \mathrm{cycle} \mathrm{at} \mathrm{room} \mathrm{temperature} \mathrm{of} 22{ }^{\circ} \mathrm{C}$. Water and food were available ad libitum at all times. After 14 weeks of HFD, DIO mice were randomly allocated to either sham, SG, or RYGB surgery. Surgical anesthesia was induced and maintained throughout the procedure with isoflurane (2-3\% with $\left.\mathrm{O}_{2}\right)$. Preoperatively, carprofen $(3 \mathrm{mg} / \mathrm{kg}$ ) was administered. During the surgery, mice were placed on a heat pad to avoid hypothermia. For SG, the lateral $70 \%$ of the stomach was excised leaving a tubular gastric remnant in continuity with the esophagus superiorly and the pylorus and duodenum inferiorly. RYGB surgery has been performed as described earlier [23]. Briefly, the stomach was dissected just distal from the esophageal junction creating a small gastric pouch. The native stomach remained connected to the duodenum and was closed using 9-0 nylon suture (Ethilon, Johnson \& Johnson, Livingston, UK). The jejunum was then incised 3-4 cm distal from the ligament of Treitz. The upper pouch of the stomach was anastomosed to the jejunum via side-to-end anastomosis, creating an alimentary limb. Sham surgery consisted of midline laparotomy and suturing. All laparotomies were closed using 4-0 Vicryl suture (Ethilon) and mice recovered on a heating pad.

\section{Postoperative care and postoperative diets}

After surgery, mice were single-housed for the remainder of the experiment and monitored daily for the first 7 days after surgery. All surgical groups, including shams, received injections of carprofen $(3 \mathrm{mg} / \mathrm{kg})$, once daily, for 2 days postoperatively. The mice received crushed pellet diet for 2 days after the surgery, followed by a low-fat diet (LFD, E15051 EF R/M, Ssniff Gmbh, Soest, Germany, containing $0.9 \%$ calcium and $1500 \mathrm{IU} / \mathrm{kg}$ vit $\mathrm{D}_{3}, 9 \% \mathrm{kcal}$ fat, $4.4 \mathrm{kcal} / \mathrm{g}$ ). The reason for switching to LFD was threefold. Firstly, it better reflects the clinical reality in which patients need to switch to an LFD in order to avoid dumping and steatorrhea [24]. Secondly, keeping mice on an HFD in particular after bypass would result in fat malabsorption [25], which is known to induce calcium malabsorption. Thirdly, in order to match the weight loss between the surgical and the sham groups, we would have to restrict the sham mice to such extent on an HFD that the calcium intake of the shams would be much lower than in the surgical groups.

At 2 and 8 weeks after the surgery, respectively, 6 and 9 mice per group (Sham, SG, and RYGB) were sacrificed, through $\mathrm{CO}_{2}$ inhalation followed by cardiac puncture (Fig. 1a). In addition, for the diet fortification study, 12 mice per group (Sham, SG, and RYGB) were kept on a diet either enriched with calcium citrate (containing 2\% calcium) or calcium citrate and vitamin $\mathrm{D}_{3}$ (containing $2 \%$ calcium and $15,500 \mathrm{IU} / \mathrm{kg}$ vit $\mathrm{D}_{3}$ ) from postoperative day 3 until sacrifice (Fig. 4a).

\section{Indirect calorimetry}

Six weeks after surgery, mice on LFD were single-housed for 7 days to adapt to specific drinking/feeding baskets. Subsequently, the mice were individually housed in automated cages for indirect calorimetry (TSE Systems, Bad Homburg, Germany) in a room at $22^{\circ} \mathrm{C}$ ambient temperature and a 12/12 h light/dark cycle [26], with ad libitum access to food and water. Ambulatory activity was recorded over a $72 \mathrm{~h}$ period, but only the last $48 \mathrm{~h}$ were used for calculations, to exclude new cage environment bias.

\section{Serum and tissue collection}

One day before sacrifice, all mice were housed in individual metabolic cages (Tecniplast, Buguggiate, Italy) to measure 


\section{A Experimental design on LFD unfortified diet}

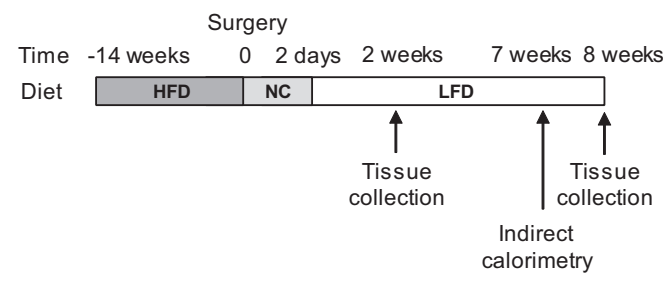

D 2 weeks
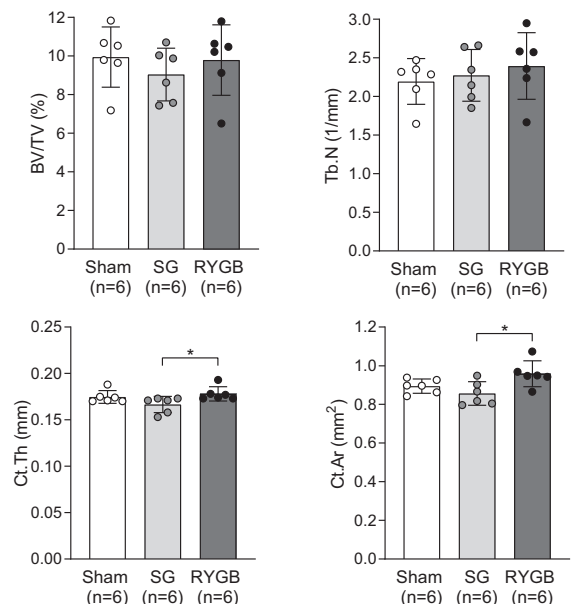

\section{E 8 weeks}
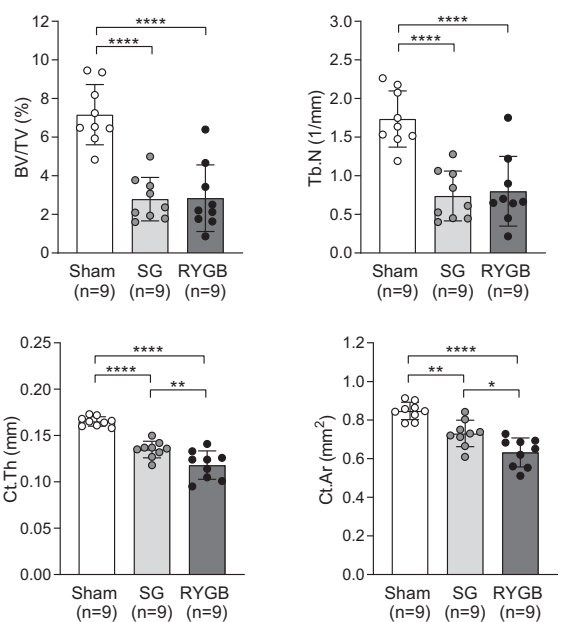
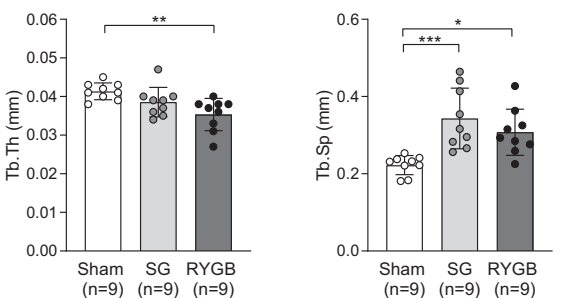

B Body Weight
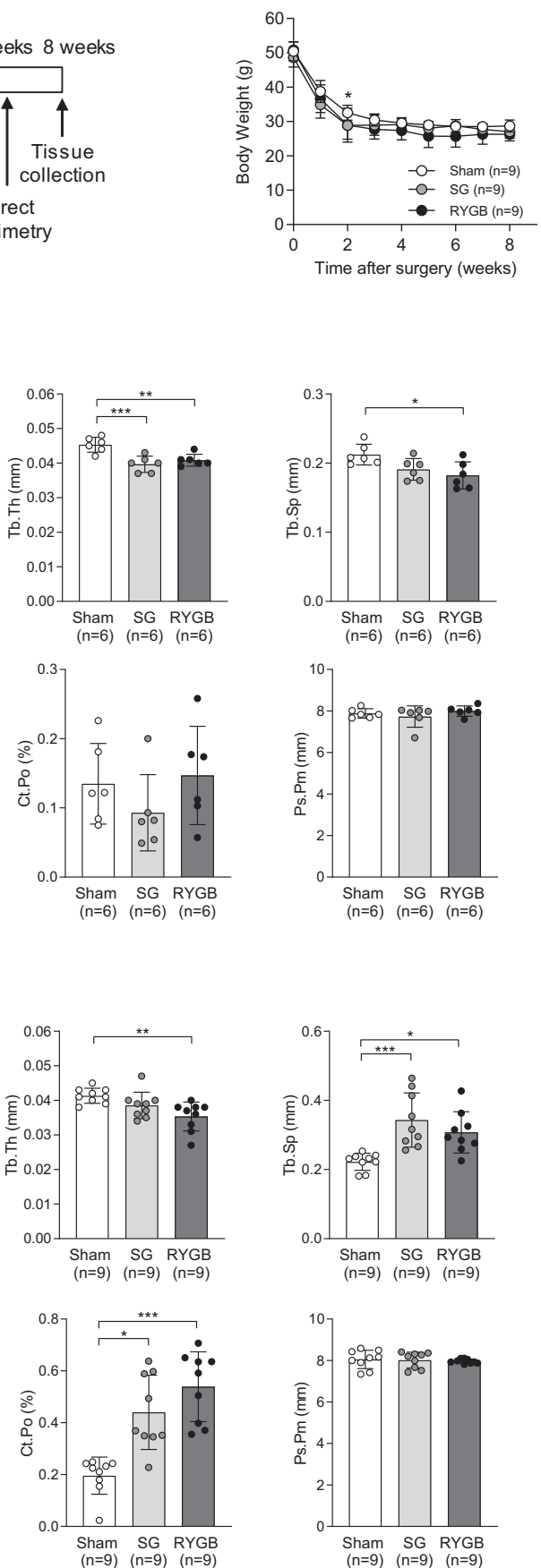

C Activity

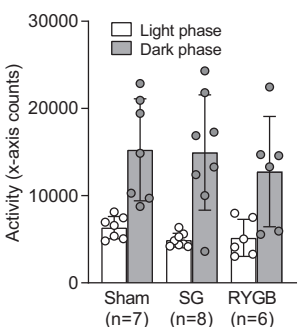

F $\quad$ MCT 8 weeks
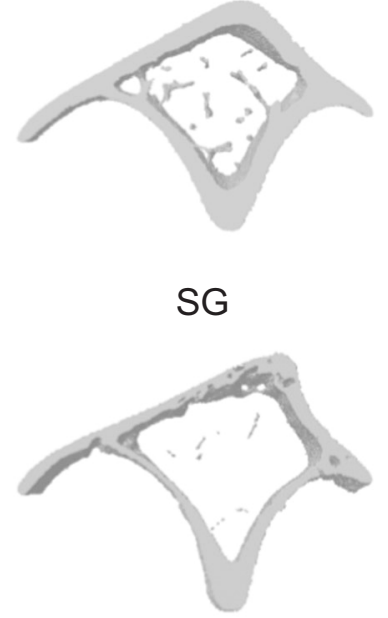

RYGB

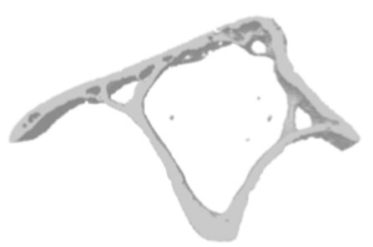

Fig. $1 \mathrm{BW}$, activity, and bone parameters after sham, SG, and RYGB. a Experimental design study (High-fat diet (HFD), normal chow (NC), and low-fat diet (LFD)). b Postoperative body weight of Sham, SG, and RYGB operated mice. c Activity during $48 \mathrm{~h}$ period, separated by light and dark phase, 7 weeks after surgery. d Quantification of trabecular and cortical bone parameters 2 weeks after surgery with $\mu \mathrm{CT}$ : bone volume/total volume (BV/TV), trabecular number (Tb. $\mathrm{N}$ ), trabecular thickness (Tb.Th), trabecular separation (Tb.Sp), cortical thickness (Ct.Th), cortical area (Ct.Ar), cortical porosity (Ct. Po), periosteal perimeter (Ps.Pm). e Trabecular and cortical bone parameters 8 weeks after surgery. $\mathbf{f}$ Representative cross-sectional 3D $\mu \mathrm{CT}$ images of the proximal tibia 8 weeks after surgery. Data represented as mean \pm SD. Statistical analysis was done by two-way ANOVA (b, c) and one-way ANOVA or Kruskal-Wallis test (d, e). $* p<0.05, * * p<0.01, * * * p<0.001, * * * * p<0.0001$. 
food intake and collect $24 \mathrm{~h}$ urine and feces samples. Mice were sacrificed through $\mathrm{CO}_{2}$ inhalation, followed immediately by blood collection through cardiac puncture. Duodenum, jejunum, and ileum were isolated as the intestinal parts adjacent to the pylorus, $13 \mathrm{~cm}$ distal to the pylorus and adjacent to cecum, respectively. The dissected intestinal parts, kidneys and femur were immediately snap frozen in liquid nitrogen and stored at $-80^{\circ} \mathrm{C}$ for further gene expression analysis by quantitative RT-PCR. Tibiae were analyzed by microcomputed tomography $(\mu \mathrm{CT})$ and histomorphometry.

\section{Microcomputed tomography analysis}

Proximal tibia $\mu \mathrm{CT}$ images were taken on the high resolution Skyscan 1172 system (Bruker, Kontich, Belgium). The scanner X-ray source was set at a voltage of $50 \mathrm{kV}$ and a current of $200 \mu \mathrm{A}$ and a $0.5 \mathrm{~mm}$ aluminum filter was applied. Scans were taken with a pixel size of $5 \mu \mathrm{m}$. Data were analyzed using cone-beam reconstruction software (NRecon software, Skyscan, Bruker). 3D morphometric analysis was performed on tibia in manually selected volumes of interest, between 0.5 and $2 \mathrm{~mm}$ distal from the growth plate for trabecular parameters and between 2.5 and $3 \mathrm{~mm}$ for cortical parameters. All measurements were performed to the guidelines of the American Society for Bone and Mineral Research [27]. 3D models were constructed with CTvol software (Bruker).

\section{Histomorphometry}

Left tibiae were fixed in Burkhardt's solution, embedded undecalcified in methyl methacrylate and sectioned at $4 \mu \mathrm{m}$. Unstained sections were used to analyze calcein labeling. Labeling was achieved through an intraperitoneal injection of calcein (16 mg/kg BW; Sigma-Aldrich) 4 and 1 days before sacrifice in all mice. Histomorphometric analysis was performed as described [28], using a Zeiss Axiovert microscope and an Axiovision (v6.1.0) image analyzing system and expressed according to the American Society for Bone and Mineral Research standardized histomorphometry nomenclature [29].

\section{Serum and tissues analyses}

Serum and urine calcium (Arsenazo III method), phosphate (UV molybdate assay) and creatinine (Jaffe IDMS Traceable method) levels were determined using an AU640 Biochemistry Analyzer (Beckmann Coulter, Brea, USA). Serum levels of osteocalcin (OC) were measured using an in-house radioimmunoassay. Serum PTH (Immutopics, San Clemente, USA), Fibroblast growth factor 23 (FGF23, Kainos Laboratories Inc., Tokyo, Japan) and C-terminal telopeptide (CTx, RatLaps, Tyne \& Wear, UK) levels were determined by
ELISA. 25(OH)D and $1,25(\mathrm{OH})_{2} \mathrm{D}$ levels were measured by LC-MS/MS at the University Hospital of Leuven. Total RNA of tissues was extracted with TRIzol (ThermoFisher Scientific, Waltham, USA) followed by phenol/chloroform purification. cDNA was synthesized using reverse transcriptase SuperScript II RT (ThermoFisher Scientific) and qRT-PCR was performed using a StepOne real-time PCR system (ThermoFisher Scientific) and Fast SYBR Green, Mastermix (Qiagen, Venlo, The Netherlands) or TaqMan mastermix (Life technologies, Ghent, Belgium). Gene expression was normalized for the expression of the housekeeping gene hypoxanthine-guanine phosphoribosyltransferase (Hprt) by using $\Delta \Delta \mathrm{Ct}$ quantification method [30]. Primer sequences are provided in Supplementary Table 1. Feces were dried at $100^{\circ} \mathrm{C}$ overnight and then reduced to ashes at $500{ }^{\circ} \mathrm{C}$ for $4 \mathrm{~h}$. The ash was dissolved in $10 \mathrm{ml} 1 \mathrm{~N} \mathrm{HCl}$. Relative calcium absorption was calculated as: [(absolute calcium intake $(\mathrm{mg})$ - absolute calcium in feces $(\mathrm{mg})) /$ calcium intake $(\mathrm{mg})] \times 100$. Urinary calcium excretion was calculated as: $100 \times([\mathrm{Ca}]$ urine/[Ca]plasma $) /([\mathrm{Crea}]$ urine/ [Crea]plasma), and analogous for phosphate excretion.

\section{Statistical analysis}

Data are expressed as mean \pm standard deviation (SD). Statistical analyses were performed with GraphPadPrism 7.0. Data were tested for outliers (ROUT method). Normality was tested by Shapiro-Wilk test. Accordingly, data were compared by one- or two-way Analysis of variance (ANOVA), followed by post-hoc analysis with Bonferroni multiple-comparison test, in case of normality or Kruskal-Wallis test if data were not distributed normally. Differences were considered statistically significant at $p<0.05$. As no statistical differences were found between mice that where fed with diet fortified with calcium citrate versus diet fortified with calcium and vitamin D, we decided to pool both diet groups for the statistical analysis. Power analysis showed that a sample size of 6 mice is sufficient per group to detect a $20 \%$ change in cortical thickness between groups with $\alpha=0.05$ and power $=90 \%$, based on means and standard deviations reported by Sinnesael et al. [31]. The investigator was not blinded to the group allocation.

\section{Study approval}

All experiments were approved by the Animal Ethics Committee of the University of Leuven (P068/2016) and performed according to the ARRIVE guidelines.

\section{Figure art}

Schematics included in the figures were created using Servier Medical Art templates, which are licensed under a Creative Commons Attribution 3.0 Unported License; https://smart.servier.com 


\section{Results}

\section{Mice on unfortified diet}

\section{Weight loss}

Eight weeks postoperatively, body weight (BW) was similar in mice that underwent sham, SG, or RYGB surgery with $28.7 \pm 1.8,27.9 \pm 1.9$, and $26.3 \pm 1.9 \mathrm{~g}$, respectively. Two weeks postoperatively, sham mice $(32.6 \pm 2.2 \mathrm{~g})$ were slightly heavier than the mice that underwent SG $(28.9 \pm$ $4.1 \mathrm{~g} ; p=0.01)$ or RYGB $(29.0 \pm 5.0 \mathrm{~g} ; p=0.01)$ (Fig. 1b). Most of the weight was lost in the first 2 weeks following the switch to LFD. Thereafter, BW stabilized.

\section{Physical activity}

Physical activity measured at 7 weeks after the surgery did not differ between the surgical groups either in dark or light phase (Fig. 1c).

\section{Effects on bone}

Two weeks after the switch to LFD, $\mu \mathrm{CT}$ analysis showed that trabecular and cortical bone parameters were not substantially altered in the mice that underwent the surgical interventions compared with sham (Fig. 1d). Although trabecular thickness was slightly lower after SG $(0.040 \pm$ $0.002 \mathrm{~mm} ; p=0.0009)$ and RYGB $(0.041 \pm 0.001 \mathrm{~mm} ; p=$ $0.006)$ compared with sham $(0.045 \pm 0.002 \mathrm{~mm})$, there was no significant difference in trabecular bone volume/total volume (BV/TV) between the surgical and sham group.

Eight weeks after surgery, trabecular and cortical bone mass were significantly lower in the mice that underwent SG $(-61 \% ; p<0.0001$ for BV/TV and $-18 \% ; p<0.0001$ for Ct.Th) and RYGB ( $-60 \%$; $p<0.0001$ for BV/TV and $-28 \% ; p<0.0001$ for $\mathrm{Ct}$.Th) compared with sham mice. Between SG and RYGB, trabecular number, thickness, separation, and cortical porosity did not differ, whereas cortical thickness and cortical area were significantly lower after RYGB $(-12 \% ; p=0.009$ for Ct.Th and $-13 \% ; p=$ 0.01 for Ct.Ar) compared with SG (Fig. 1e, f).

\section{Effects on bone formation and resorption markers}

Two weeks after the surgery, no differences were found in serum OC levels, a marker of bone formation (Supplementary Table 2). Serum CTx levels, a marker for bone resorption, were significantly higher in mice that underwent SG $(28.8 \pm 4.3 \mathrm{ng} / \mathrm{ml} ; p=0.02)$, but not RYGB $(26.4 \pm$ $5.4 \mathrm{ng} / \mathrm{ml})$, compared with sham $(21.0 \mathrm{ng} / \mathrm{ml})$ (Supplementary Table 2). Eight weeks after surgery, OC levels were markedly higher in mice that underwent RYGB $(60.0 \pm$
$26.0 \mathrm{ng} / \mathrm{ml} ; p=0.02)$ when compared with mice after sham $(32.2 \pm 17.0 \mathrm{ng} / \mathrm{ml})$ or SG $(33.4 \pm 11.2 \mathrm{ng} / \mathrm{ml})$ procedure. Histomorphometry of dynamic bone parameters showed a higher bone formation rate (BFR/BS) both after SG $\left(0.043 \pm 0.025 \mu^{3} / \mu \mathrm{m}^{2} / \mathrm{d} ; \quad p=0.0006\right)$ and RYGB $\left(0.045 \pm 0.011 \mu \mathrm{m}^{3} / \mu \mathrm{m}^{2} / \mathrm{d} ; \quad p=0.0004\right)$ compared with sham $\left(0.005 \pm 0.006 \mu \mathrm{m}^{3} / \mu \mathrm{m}^{2} / \mathrm{d}\right)$, with an increase in mineral apposition rate (MAR) and mineral surface (MS) (Supplementary Fig. 1).

\section{Food, calcium, and vitamin D intake}

Both at 2 and 8 weeks, food intake was similar between all groups (Fig. 2a, b), which also implies that there was no statistical difference in absolute calcium and vitamin D intake between the groups.

\section{Effects on calcium and vitamin D handling}

We did not observe any differences in calcium, phosphate, creatinine, PTH, FGF23, and vitamin D levels 2 weeks after surgery (Fig. 2a and Supplementary Table 2). At 8 weeks, SG and RYGB mice had slightly lower phosphate $(8.5 \pm$ $0.7 \mathrm{mg} / \mathrm{dl} ; p=0.001$ for $\mathrm{SG}$ and $8.9 \pm 1.1 \mathrm{mg} / \mathrm{dl} ; p=0.01$ for RYGB) and 25(OH)D $(14.1 \pm 1.2 \mathrm{ng} / \mathrm{ml} ; p$ for $\mathrm{SG}$ and $16.2 \pm 4.5 \mathrm{ng} / \mathrm{ml}$ for RYGB) serum levels compared with sham mice (Supplementary Table 2). There was a trend towards higher PTH levels in RYGB compared with sham mice at 8 weeks postoperatively $(p=0.064)$, but this failed to reach statistical significance (Fig. 2b). Both at 2 and 8 weeks after surgery, relative intestinal calcium (5.2-fold increase; $p=0.001$ and 3.3-fold increase; $p=0.02$, respectively) and phosphate absorption (2.6-fold increase; $p=0.0005$ and 2.3-fold increase, $p=0.003$, respectively) were markedly higher in RYGB compared with sham mice (Fig. 2a, b). After SG, changes in phosphate and calcium absorption were less pronounced. Two weeks after surgery, phosphate absorption (1.8-fold increase; $p=0.048$ ) was higher in SG mice with also a clear trend for a higher calcium absorption (3.2-fold increase; $p=0.078$ ). This difference attenuated at the 8 weeks' time-point (Fig. 2a, b). In the RYGB mice, RNA levels confirmed an upregulation of phosphate transporters compared with sham at the 2 weeks' time-point (Fig. 2c). At 8 weeks there was a clear upregulation of calcium transporters after both SG (S100g) and RYGB (Trpv6 and S100g) throughout the small intestine (Fig. 2d) compared with sham.

With respect to renal handling of minerals, 2 weeks after surgery, the calcium excretion was higher after RYGB (2.0fold increase; $p=0.01$ ) compared with sham whereas phosphate excretion was higher in the SG (1.9-fold increase; $p=0.03$ ), but not the RYGB mice (Fig. 3a). However, this was in contrast with the transcriptome which 
A

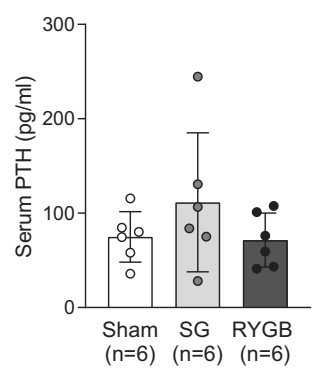

B

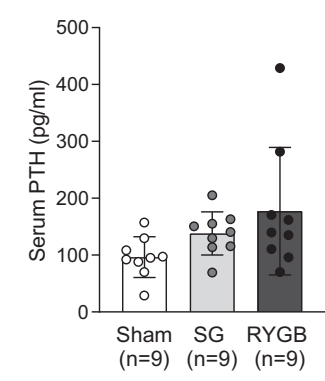

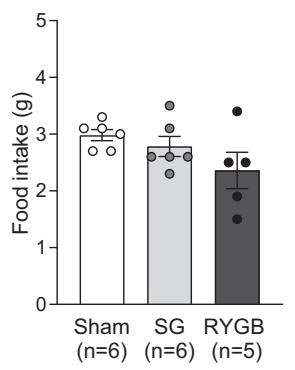

$(n=6) \quad(n=6) \quad(n=5)$

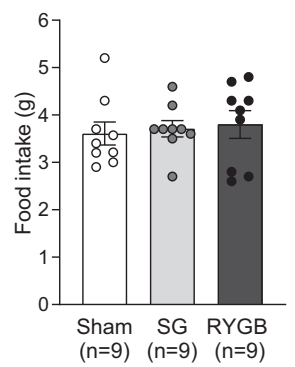

C

Duodenum

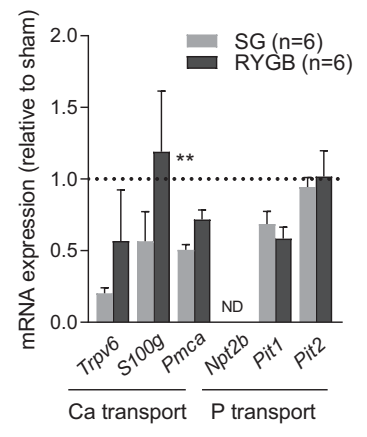

D

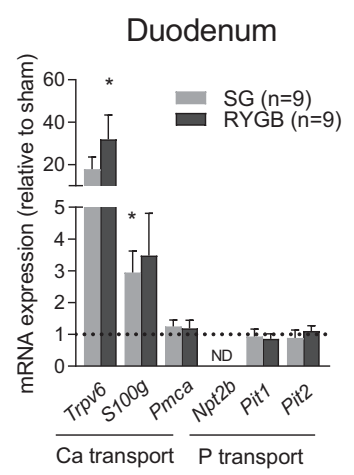

2 weeks
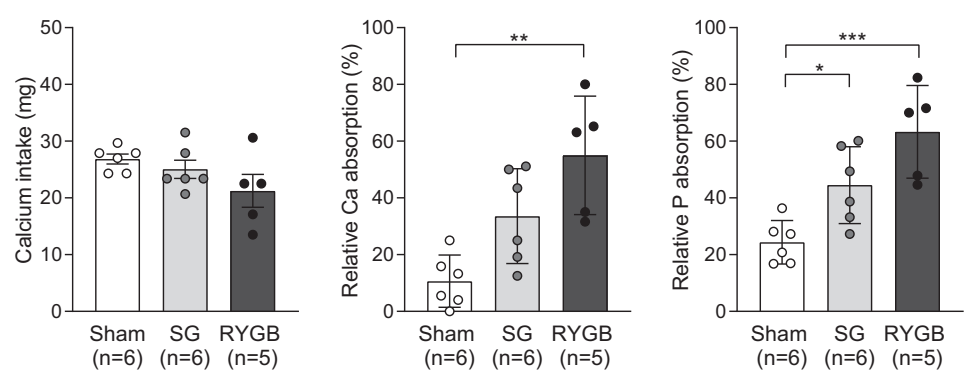

8 weeks
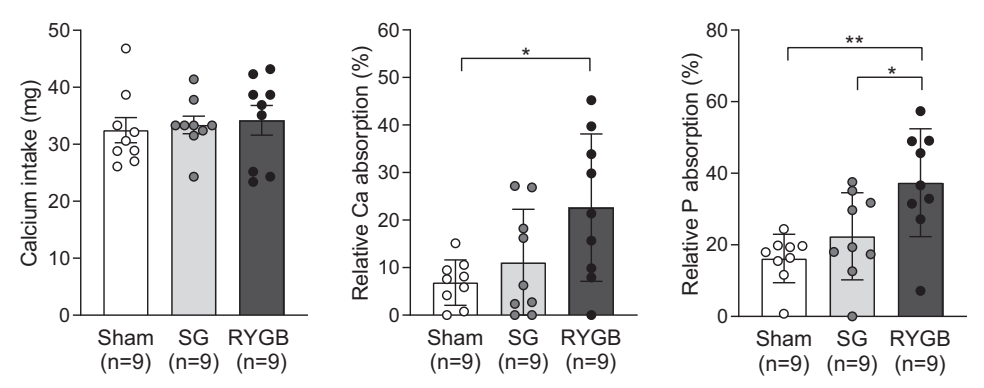

\section{2 weeks}

Jejunum
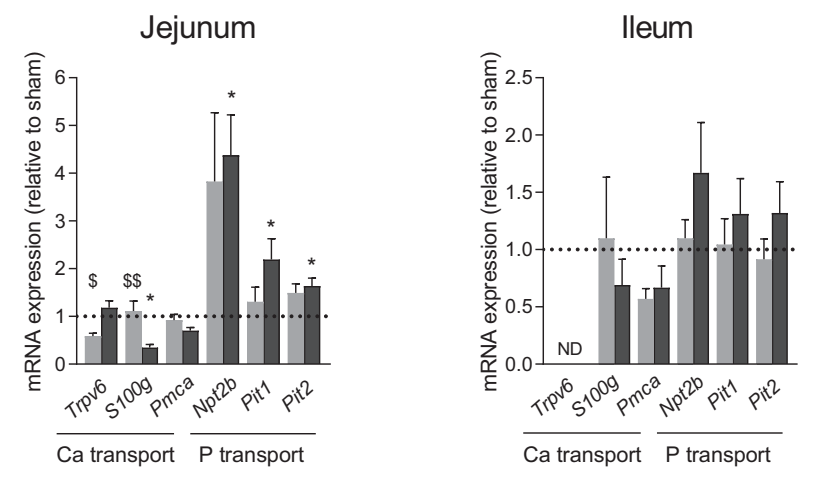

\section{8 weeks}
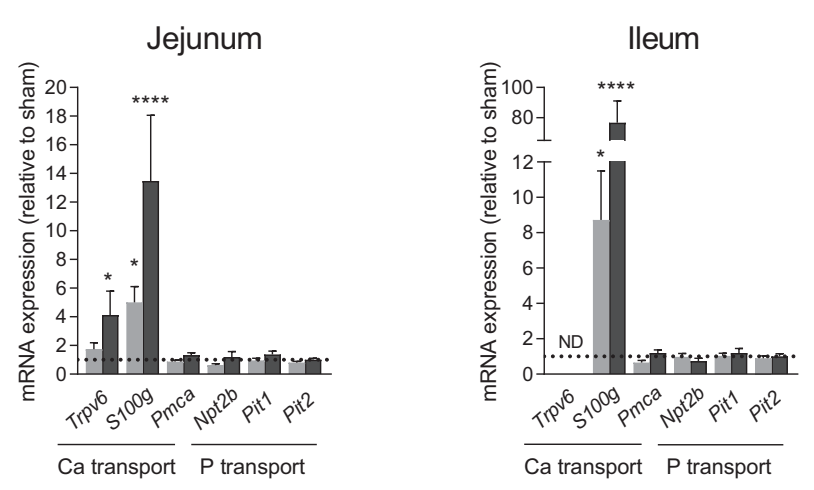

showed an overall higher expression of calcium and phosphate transporters after SG (Fig. 3c). Eight weeks after the surgery, renal calcium and phosphate excretion were higher in the RYGB (2.1-fold increase; $p=0.01$ and 1.9-fold increase; $p=0.007$, respectively) versus sham mice (Fig. $3 b$ ), with no difference between SG and sham. Gene 
Fig. 2 Serum PTH, food intake, calcium intake, intestinal absorption, and gene expression analysis 2 and 8 weeks after surgery. a Serum PTH, food intake, calcium intake, relative calcium, and phosphate absorption 2 weeks after surgery. b Serum PTH, food intake, calcium intake, relative calcium, and phosphate absorption 8 weeks after surgery. c Gene expression analysis of proteins involved in calcium (Trpv6, S100g, and Pmca) and phosphate transport (Npt2b, Pit1, and Pit2), 2 weeks after surgery in duodenum, jejunum, and ileum, comparing SG/RYGB fold change with sham (indicated by the dotted line). d Gene expression analysis of proteins involved in calcium and phosphate transport, 8 weeks after surgery in duodenum, jejunum, and ileum, comparing SG/RYGB fold change with sham (indicated by the dotted line). Data represented as mean \pm SD. ND not determined. Statistical analysis done with one-way ANOVA. ${ }^{*} p<$ $0.05, * * p<0.01, * * * p<0.001, * * * * p<0.0001$. In $\mathbf{c}$ and $\mathbf{d}$ : *significantly different from sham, \$significantly different from RYGB $\left({ }_{p}<0.05,{ }^{\$} p<0.01\right)$.

expression analysis showed higher expression of the active calcium transporters Trpv5 and S100g in RYGB mice and lower expression of the phosphate transporter Pit 2 in both SG and RYGB compared with sham mice (Fig. 3d).

\section{Mice on fortified diet}

\section{Effects on bone}

Fortification with calcium citrate and vitamin D (Fig. 4a) prevented trabecular and cortical bone loss 8 weeks after SG or RYGB (Fig. 4b, c). Fortification also improved all bone parameters in the sham group. As a result, the sham mice on fortified diet performed better on all bone parameters when compared with the mice that were fed fortified diet after SG or RYGB. Fortification of the diet with calcium citrate and vitamin D lowered OC levels 8 weeks after RYGB $(22.7 \pm 18.6 \mathrm{ng} / \mathrm{ml})$ to levels comparable with sham $(32.2 \pm$ $17.0 \mathrm{ng} / \mathrm{ml}$ ), suggesting less bone formation (Supplementary Table 2). However, bone resorption was increased with higher CTx levels in RYGB $(35.0 \pm 19.4 \mathrm{ng} / \mathrm{ml} ; p=0.004)$, compared with sham $(15.4 \pm 3.5 \mathrm{ng} / \mathrm{ml})$.

\section{Effect on calcium and vitamin D handling}

Fortified LFD increased serum calcium levels in the SG $(10.9 \pm 0.3 \mathrm{mg} / \mathrm{dl} ; p=0.049)$ and RYGB $(11.3 \pm 1.2 \mathrm{mg} / \mathrm{dl}$; $p=0.0005)$ mice compared with sham $(10.0 \pm 0.4 \mathrm{mg} / \mathrm{dl})$ (Supplementary Table 2). Serum phosphate, creatinine, PTH, and FGF23 levels did not change when mice were fed with fortified LFD. The fortified diet had no effect on relative intestinal calcium and phosphate absorption in the sham group (Fig. 5a), whereas, after SG and RYGB absorption of calcium was enhanced, though this only reached statistical significance in the SG mice. After RYGB, phosphate absorption decreased with fortification.

Throughout the small intestine, gene expression of transporters involved in active calcium transport, decreased with fortification (Fig. 5b). Gene expression of transporters involved in phosphate transport showed few differences (Fig. 5b).

Renal calcium excretion increased strongly in sham mice on fortified diet (Fig. 6a), but was not altered in the SG and RYGB mice. On the other hand, phosphate excretion decreased in all groups that received fortified diets, reflecting the decreased intestinal phosphate absorption. Gene expression analysis in the kidney showed an increased expression of Trpv5 and Npt2c with fortification after SG (Fig. 6b).

\section{Summary}

To summarize, 2 weeks after surgery, bone mass was similar between the mice that underwent sham, SG, or RYGB (Fig. 7a). Although, intestinal calcium absorption and renal calcium excretion were already increased, no changes in active calcium transporters could be detected in either organ.

Eight weeks after surgery, bone mass was lower in the mice that had undergone a SG or RYGB compared with the sham mice (Fig. 7b, black text) despite a markedly increased absorption of calcium, possibly due to the observed upregulation of active calcium transporters in the intestine, in particular after RYGB. In the kidney, calcium transporters were upregulated after SG and RYGB but this failed to prevent the increased calcium excretion.

On a fortified diet, the bone loss after SG and RYGB was prevented (Fig. 7b, blue text). Calcium absorption from the intestine was increased and calcium excretion from the kidney remained elevated.

\section{Discussion}

We set out to study the bone effects of bariatric surgery using mouse models for SG and RYGB. We compared mice that lost weight through SG and RYGB to weight-matched sham operated mice. Similar weight loss was achieved by switching all the mice to LFD after the surgery. The amount of food ingested post-surgery remained the same in the three experimental groups, which ensures similar vitamin D and calcium intake. In addition, we assessed whether fortification of the diet with calcium citrate and vitamin D could prevent the loss of bone. To investigate the dynamics of bone loss, we used two time-points: 2 and 8 weeks after surgery. Because of the invasiveness of the procedures to assess bone resorption and formation markers and bone parameters, mice had to be sacrificed at both time-points. However, the cross-sectional design of our study is its greatest strength as it allows to compare mice of the same age that received the same food resulting in identical weight 
Fig. 3 Renal calcium excretion and gene expression analysis 2 and 8 weeks after surgery. a Relative calcium and phosphate excretion 2 weeks after surgery.

b Relative calcium and phosphate excretion 8 weeks after surgery. c Gene expression analysis of proteins involved in calcium (Trpv5, S100g, and Pmca) and phosphate reabsorption (Npt2a, Npt2c, Pit1, and Pit2) in the kidney, 2 weeks after surgery, comparing SG/RYGB fold change with sham (indicated by the dotted line). d Gene expression analysis of proteins involved in calcium and phosphate reabsorption in the kidney, 8 weeks after surgery, comparing SG/RYGB fold change with sham (indicated by the dotted line). Data represented as mean $\pm \mathrm{SD}$. Statistical analysis done with one-way ANOVA. $* p<0.05$, $* * p<0.01$. In $\mathbf{c}$ and $\mathbf{d}$ : *significantly different from sham, \$significantly different from RYGB $\left({ }^{\$} p<0.05\right)$.
A

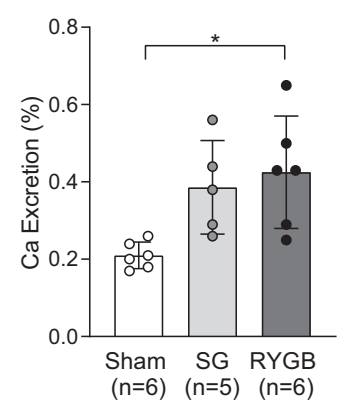

2 weeks

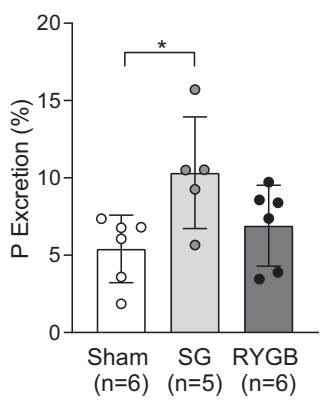

C

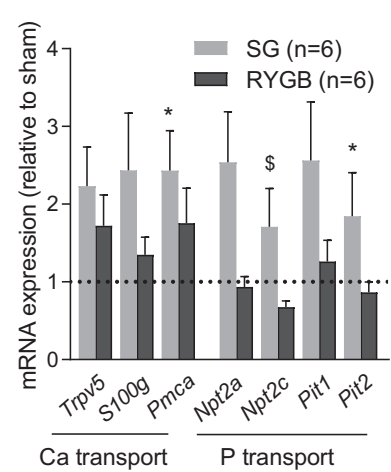

B

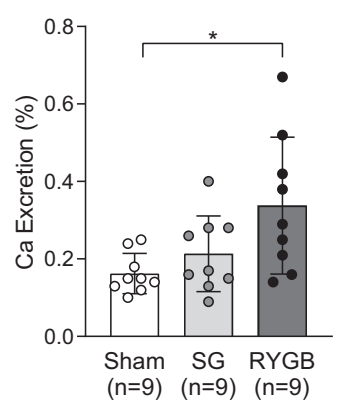

8 weeks

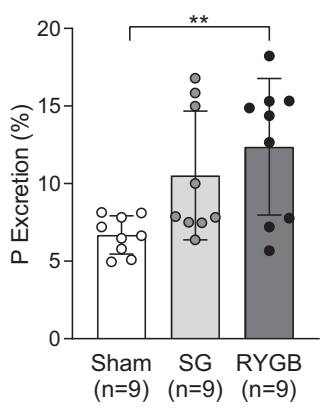

D

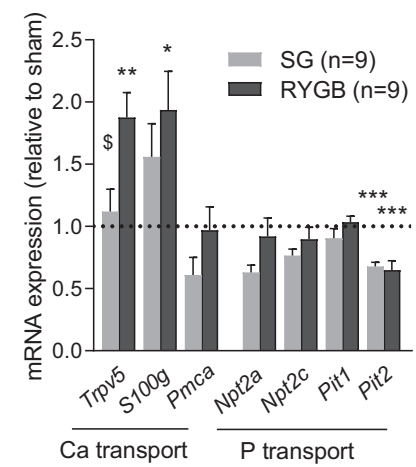

loss, thus permitting to evaluate the effect of SG and RYGB per se. Consequently, the differences observed between groups cannot be attributed to aging, dietary changes, or difference in bone loading due to weight loss.

Despite the fact that almost all weight was lost in the first 2 weeks after the surgery and stabilized thereafter, no substantial bone loss was observed within those 2 first weeks. Only trabecular thickness showed a significant decrease at the 2 weeks' time-point, which could indicate the initiation of bone loss, but cortical and trabecular bone were overall well preserved. However, 8 weeks after surgery, both SG and RYGB induced substantial bone loss.

We now demonstrate that no malabsorption of calcium occurred after either surgery on LFD. On the contrary, calcium absorption from the gut was strongly increased after RYGB and, to a lesser extent, SG, even with a similar calcium intake after surgery compared with sham group. Moreover, no substantial increase of PTH was observed 2 weeks after SG or RYGB compared with the sham mice. Eight weeks after surgery, a trend towards increased PTH after RYGB was observed, which however did not reach statistical significance, possibly due to the high variability in PTH levels. Furthermore, none of the bone parameters showed a negative correlation with $\mathrm{PTH}$, which would be expected if PTH had a major role in the bone loss after surgery.
The current study also suggests that compensatory mechanisms are put in place to maintain calcium status after surgery. Eight weeks after surgery, when strong bone loss was detected, active intestinal calcium absorption was upregulated, clearly showing attempts to restore the bone loss and/or prevent further bone loss. Shortly after surgery, neither bone loss nor upregulation of active intestinal calcium transport were yet detected, which suggests that a different mechanism was responsible for the higher calcium absorption at this time-point. A possible mechanism is calcium absorption through a depolarization-dependent calcium channel, $\mathrm{Ca}_{\mathrm{v}} 1.3$, which is activated independently of vitamin D and TRPV6. We hypothesize that the observed increased glucose absorption after RYGB [32-34] will also result in a higher sodium absorption through Sodium-glucose linked transporter (SGLT1), depolarizing the membrane. This depolarization will then activate the calcium channels $\mathrm{Ca}_{\mathrm{v}} 1.3$, leading to higher calcium absorption as described by Kellet et al. [35]. However, we were unable to test this hypothesis in our setup. Because substantial bone loss was only observed 8 weeks after SG and RYGB, we decided to assess the effect of fortifying the diet with calcium citrate and vitamin D at the 8 weeks' time-point only. Our data show that fortification with extra calcium citrate does prevent bone loss, and fits with the idea that 

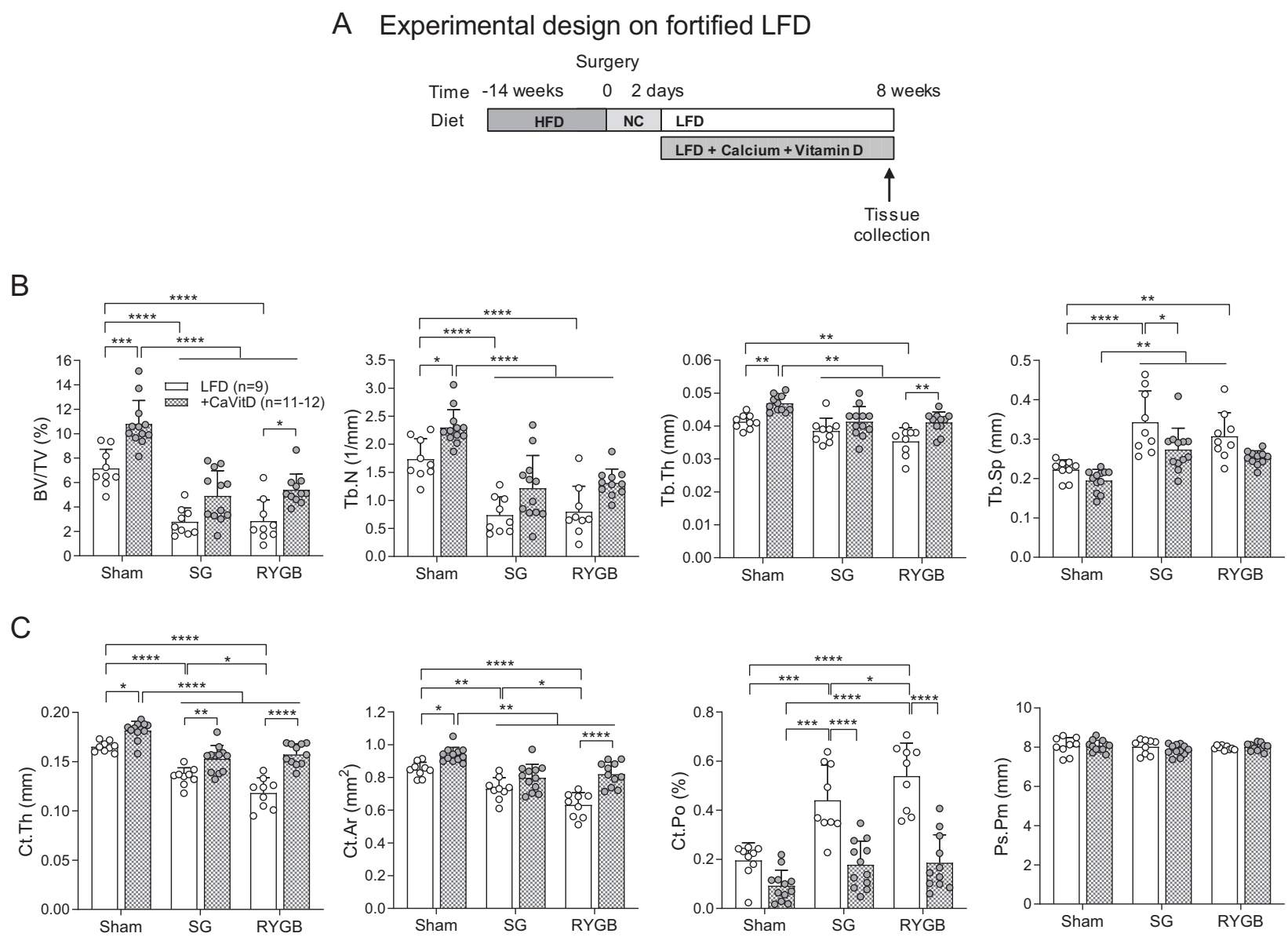

Fig. 4 Bone parameters after sham, SG, and RYGB with calcium citrate and vitamin $\mathrm{D}$ supplementation. a Experimental design on fortified diet (High-fat diet (HFD), normal chow (NC), low-fat diet (LFD)). b Quantification of trabecular bone parameters on supplementation 8 weeks after surgery with $\mu \mathrm{CT}$ : bone volume/total volume (BV/TV), trabecular number (Tb.N), trabecular thickness (Tb.Th), trabecular separation (Tb.Sp). c Quantification of cortical bone parameters on supplementation, 8 weeks after surgery with $\mu \mathrm{CT}$ : cortical

the intestinal calcium absorption is functional and trying to compensate for bone loss. In the sham group, diet fortification improved bone parameters, likely by preventing age-related bone loss. Diet fortification prevented bone loss partly in SG and RYGB mice, but did not improve bone parameters above the level of sham on unfortified LFD. The latter finding illustrates that fortifying the diet helps to prevent bone loss instigated by surgery, but does not completely rescue bone mass.

On unfortified LFD, the intestinal calcium absorption was also increased, however, this was insufficient to prevent bone loss. The even higher increased calcium absorption observed with diet fortification, indicates there might be a "relative calcium malabsorption" on unfortified LFD. However, if the bone loss could solely be attributed to calcium malabsorption, the renal calcium excretion would be expected to decrease. The observed increase of renal thickness (Ct.Th), cortical area (Ct.Ar), cortical porosity (Ct.Po), periosteal perimeter (Ps.Pm).t. Data represented as mean \pm SD. Statistical analysis was done by two-way ANOVA, which showed a significant main effect of surgery and diet and a nonsignificant interaction between factors for trabecular parameters (b) and a significant interaction between both factors for cortical parameters $(\mathbf{c}){ }^{*} p<0.05$, $* * p<0.01, * * * p<0.001, * * * * p<0.0001$ (post-hoc pairwise comparisons with Bonferroni correction).

calcium excretion is, however, relatively less important quantitatively than the increased intestinal absorption. The unexpected increase in intestinal calcium absorption, as well as, renal excretion, lead us to believe there is an unknown mechanism inducing bone resorption. In response to this induced bone loss, the intestinal calcium absorption increases to prevent bone loss. We could not explain why the renal calcium excretion was increased and believe this might be a side effect of the increased bone loss and calcium absorption which outpaces the ability of the kidney to reabsorb the excess calcium.

In contrast to our expectations, we did not find differences between the fortification of solely calcium citrate and fortification of calcium citrate and vitamin D. This lack of difference is likely due to the high amount of vitamin D already present in the standard diets used for mice, masking the added effect of extra vitamin D. 

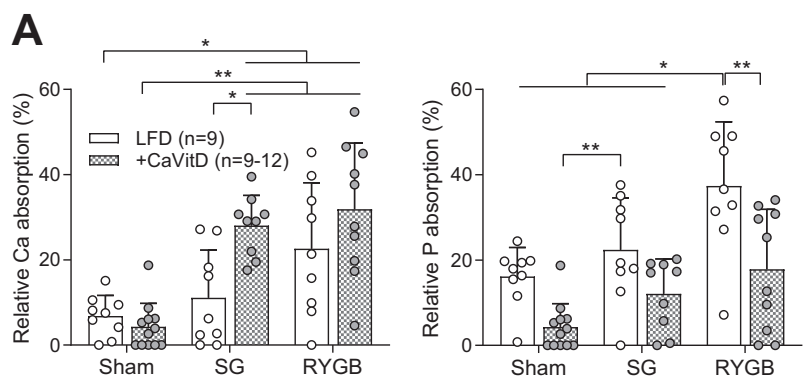

B
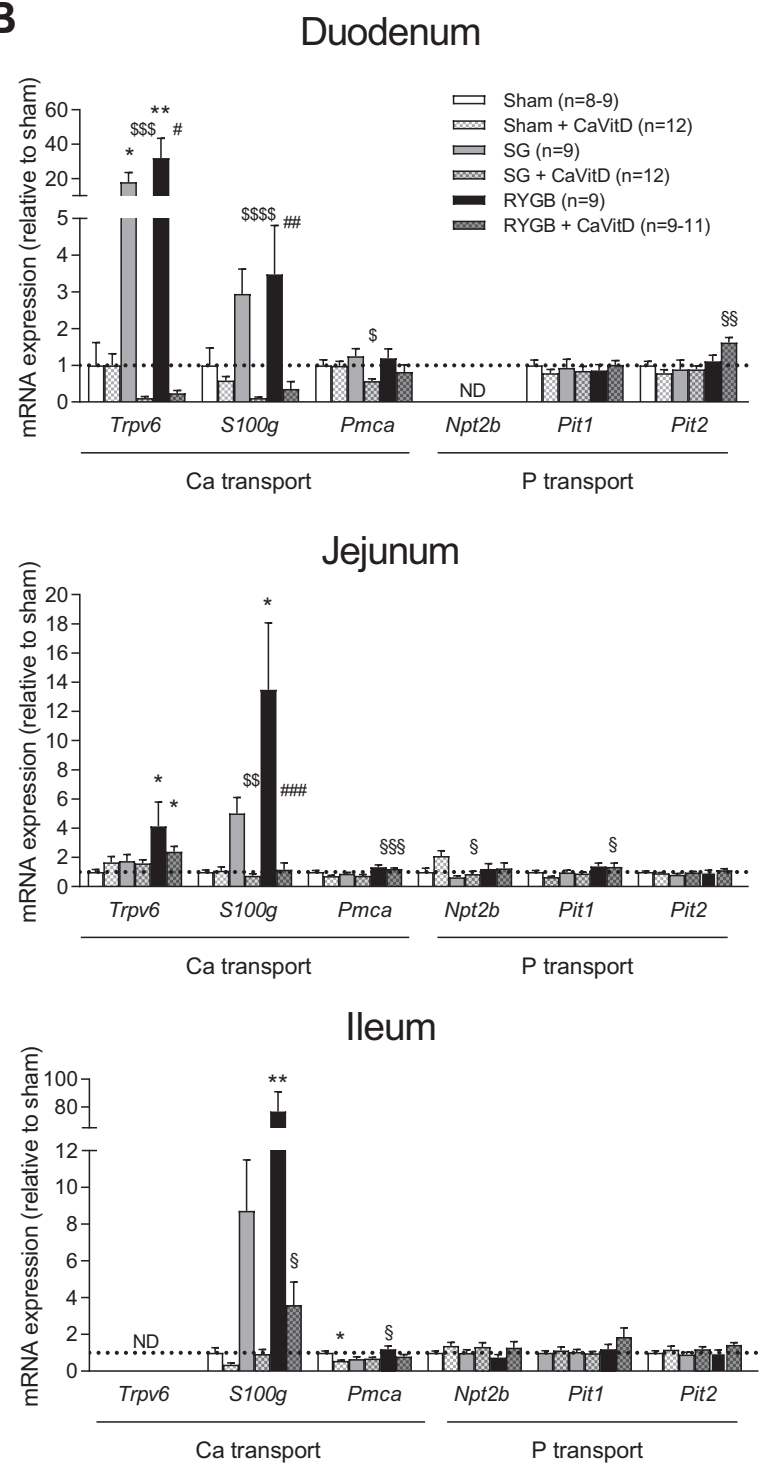

Whether these findings are relevant to the human setting remains to be confirmed. Often diet compliance in humans is poor $[36,37]$ and remaining on HFD after surgery may indeed compromise calcium absorption [38-40], thus leading to SHPT. Nonetheless, also in humans there are reports that bone loss after bariatric surgery occurs even though PTH remains within normal range [10, 17-20]. This finding supports the notion that also in humans, other
Fig. 5 Intestinal absorption and gene expression analysis 8 weeks after surgery on calcium citrate and vitamin $D$ fortified diets. a Relative calcium and phosphate absorption 8 weeks after surgery. b Gene expression analysis of proteins involved in calcium (Trpv6, $S 100 \mathrm{~g}$, and Pmca) and phosphate transport (Npt2b, Pit1, and Pit2) in duodenum, jejunum, and ileum, comparing SG/RYGB fold change with sham (indicated by the dotted line). Data represented as mean \pm SD. ND not determined. Statistical analysis done with two-way ANOVA (a), which showed a significant main effect of surgery and diet and a significant interaction between factors for calcium absorption, but not for phosphate absorption. $* p<0.05$, ** $p<0.01$, *** $p<$ 0.001 (post-hoc pairwise comparisons with Bonferroni correction). In b statistical analysis was done with one-way ANOVA: *significantly different from sham, \$significantly different from SG, " significantly different from RYGB, and ${ }^{\S}$ significantly different from Sham + CaVitD.
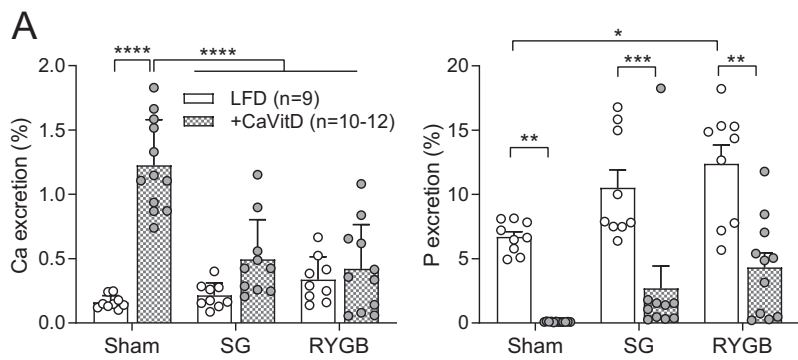

$\mathrm{B}$

Kidney

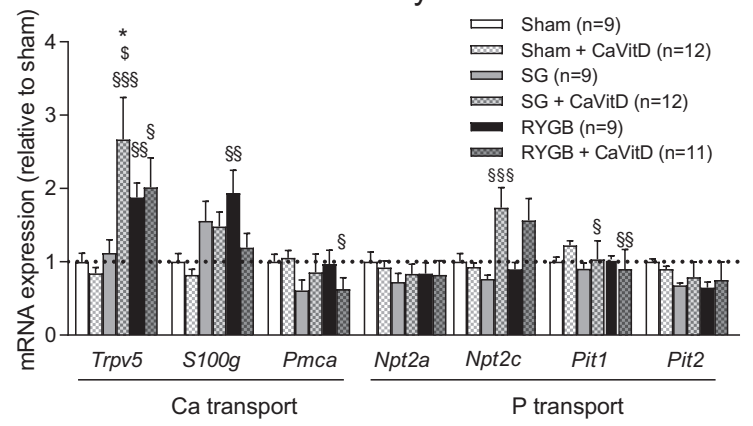

Fig. 6 Renal calcium excretion and gene expression analysis 8 weeks after surgery on calcium and vitamin $D$ fortified diets. a Relative calcium and phosphate excretion 8 weeks after surgery. b Gene expression analysis of proteins involved in calcium (Trpv5, S100g, and Pmca) and phosphate reabsorption (Npt2a, Npt2c, Pit1, and Pit2) in the kidney, comparing SG/RYGB fold change with sham (indicated by the dotted line). Data represented as mean \pm SD. Statistical analysis done with two-way ANOVA (a), which showed a significant main effect of surgery and diet and a significant interaction between factors for calcium excretion, but not for phosphate excretion. $* p<0.05, * * p<0.01, * * * p<0.001, * * * * p<0.0001$ (post-hoc pairwise comparisons with Bonferroni correction). In $\mathbf{b}$ statistical analysis was done with one-way ANOVA: *significantly different from Sham, \$ significantly different from SG, " significantly different from RYGB, and ${ }^{\S}$ significantly different from Sham + CaVitD.

mechanisms than SHPT drive bone loss after bariatric surgery, although the exact underlying mechanisms remain to be identified. However, our results do confirm the importance of calcium citrate and vitamin D supplementation after surgery in clinical practice. 


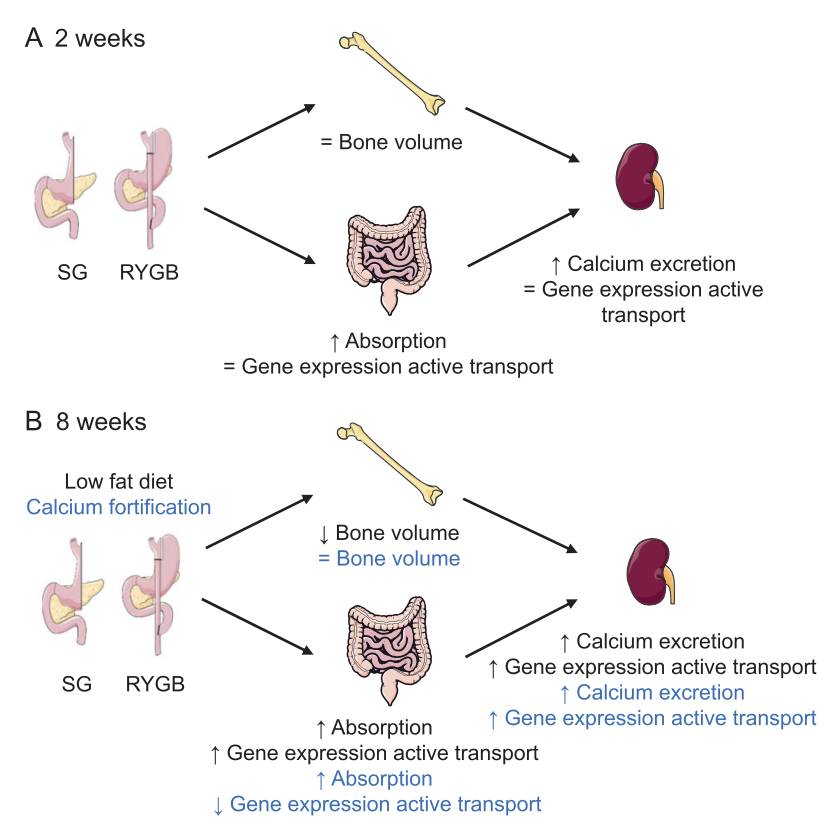

Fig. 7 Overview of changes in bones, intestines, and kidneys after SG and RYGB. a Early effects 2 weeks after surgery. b Late effects 8 weeks after surgery on LFD (black) and fortified diet (blue).

Finally, there are some limitations to our study. Firstly, the calcium absorption was measured indirectly. To confirm our results, radioactively labeled calcium should be used. However, this is a technically challenging technique in recently operated mice with altered absorption patterns and does not allow for tissue collection afterwards. Secondly, the variability in our data always seems to be higher in SG and RYGB groups, than sham groups. This might be due to the invasive nature of the surgery and variability in response, both in terms of beneficial and adverse effects of bariatric surgery, which has also been observed in clinical practice. Therefore, further studying this variability may hold the key to gain a better understanding of what drives clinical outcomes within the same surgical group and why responses differ between SG and RYGB. Lastly, the observed weight loss in mice is greater, in proportion to body mass, than what is usually seen in patients, and may limit clinical translation. However, in patients it is difficult to investigate the calcium and bone homeostasis after bariatric surgery because patients often have low vitamin D levels or SHPT already before surgery. Animal studies do allow for an ideal control group in this setting, with similar weight loss and food intake. The evidence obtained from animal studies can then be used to improve the design of clinical studies.

In conclusion, our study shows that, in mice, SG and RYGB lead to similar bone loss. Our data also demonstrate that bariatric surgery does not induce calcium malabsorption and that intestinal adaptations even lead to increased calcium absorption. Our findings underline the importance of adequate calcium intake after SG and RYGB, although this cannot prevent bone loss completely, suggesting alternative mechanisms may be at play.

Acknowledgements The authors would like to thank K. Moermans and R. Van Looveren for their histological preparation of bone samples and G. Molenberghs from the Interuniversity Institute for Biostatistics and Statistical Bioinformatics for his assistance with statistical analyses. This work was supported by the FWO (Flemish Research Council) grant numbers 1 S27317N and $1802714 N$. The authors do not have any conflicts of interest to disclose.

Funding This work was supported by the FWO (Flemish Research Council) [grant numbers $1 \mathrm{~S} 27317 \mathrm{~N}$ and $1802714 \mathrm{~N}$ ]. Bart Van der Schueren is a clinical researcher of FWO (Flemish Research Council).

\section{Compliance with ethical standards}

Conflict of interest The authors declare that they have no conflict of interest.

Publisher's note Springer Nature remains neutral with regard to jurisdictional claims in published maps and institutional affiliations.

\section{References}

1. World Health Organization. Obesity and overweight factsheet. Accessed 25 July 2019. http://www.who.int/mediacentre/fa ctsheets/fs $311 /$ en/.

2. Rousseau C, Jean S, Gamache P, Lebel S, Mac-Way F, Biertho L, et al. Change in fracture risk and fracture pattern after bariatric surgery: nested case-control study. BMJ. 2016;354:i3794.

3. Blom-Høgestøl IK, Hewitt S, Chahal-Kummen M, Brunborg C, Gulseth HL, Kristinsson JA, et al. Bone metabolism, bone mineral density and low-energy fractures 10 years after Roux-en-Y gastric bypass. Bone. 2019;127:436-45.

4. Zhang Q, Chen Y, Li J, Chen D, Cheng Z, Xu S, et al. A metaanalysis of the effects of bariatric surgery on fracture risk. Obes Rev. 2018;19:728-36.

5. Schafer AL, Kazakia GJ, Vittinghoff E, Stewart L, Rogers SJ, Kim TY, et al. Effects of gastric bypass surgery on bone mass and microarchitecture occur early and particularly impact postmenopausal women. J Bone Miner Res. 2018;33:975-86.

6. Yu EW, Lee MP, Landon JE, Lindeman KG, Kim SC. Fracture risk after bariatric surgery: Roux-en- $\mathrm{Y}$ gastric bypass versus adjustable gastric banding. J Bone Miner Res. 2017;32:1229-36.

7. Corbeels K, Verlinden L, Lannoo M, Simoens C, Matthys C, Verstuyf A, et al. Thin bones: vitamin D and calcium handling after bariatric surgery. Bone Rep. 2018;8:57-63.

8. Maghrabi AH, Wolski K, Abood B, Licata A, Pothier C, Bhatt DL, et al. Two-year outcomes on bone density and fracture incidence in patients with $\mathrm{T} 2 \mathrm{DM}$ randomized to bariatric surgery versus intensive medical therapy. Obesity. 2015;23:2344-8.

9. Carrasco F, Basfi-Fer K, Rojas P, Valencia A, Csendes A, Codoceo $\mathrm{J}$, et al. Changes in bone mineral density after sleeve gastrectomy or gastric bypass: relationships with variations in vitamin D, ghrelin, and adiponectin levels. Obes Surg. 2014;24:877-84.

10. Vilarrasa N, de Gordejuela AG, Gómez-Vaquero C, Pujol J, Elio I, San José P, et al. Effect of bariatric surgery on bone mineral density: comparison of gastric bypass and sleeve gastrectomy. Obes Surg. 2013;23:2086-91. 
11. Muschitz C, Kocijan R, Haschka J, Zendeli A, Pirker T, Geiger C, et al. The impact of vitamin $\mathrm{D}$, calcium, protein supplementation, and physical exercise on bone metabolism after bariatric surgery: the BABS study. J Bone Miner Res. 2016;31:672-82.

12. Hsin MC, Huang CK, Tai CM, Yeh LR, Kuo HC, Garg A. A casematched study of the differences in bone mineral density 1 year after 3 different bariatric procedures. Surg Obes Relat Dis. 2015;11:181-5.

13. Muschitz C, Kocijan R, Marterer C, Nia AR, Muschitz GK, Resch $\mathrm{H}$, et al. Sclerostin levels and changes in bone metabolism after bariatric surgery. J Clin Endocrinol Metab. 2015;100:891-901.

14. Pluskiewicz W, Bužga M, Holéczy P, Bortlík L, Šmajstrla V, Adamczyk P. Bone mineral changes in spine and proximal femur in individual obese women after laparoscopic sleeve gastrectomy: a short-term study. Obes Surg. 2012;22:1068-76.

15. Adamczyk $P$, Bužga M, Holéczy $P$, Švagera Z, Zonča $P$, Sievänen $\mathrm{H}$, et al. Body size, bone mineral density, and body composition in obese women after laparoscopic sleeve gastrectomy: a 1-year longitudinal study. Horm Metab Res. 2015;47:873-9.

16. Li Z, Hardij J, Evers SS, Hutch CR, Choi SM, Shao Y, et al. GCSF partially mediates effects of sleeve gastrectomy on the bone marrow niche. J Clin Investig. 2019;130:2404-16.

17. Shanbhogue VV, Støving RK, Frederiksen KH, Hanson S, Brixen $\mathrm{K}$, Gram J, et al. Bone structural changes after gastric bypass surgery evaluated by HR-pQCT: a two-year longitudinal study. Eur J Endocrinol. 2017;176:685-93.

18. Yu EW, Bouxsein ML, Putman MS, Monis EL, Roy AE, Pratt JS, et al. Two-year changes in bone density after Roux-en-Y gastric bypass surgery. J Clin Endocrinol Metab. 2015;100:1452-9.

19. Bredella MA, Greenblatt LB, Eajazi A, Torriani M, Yu EW. Effects of Roux-en-Y gastric bypass and sleeve gastrectomy on bone mineral density and marrow adipose tissue. Bone. 2017;95:85-90.

20. von Mach MA, Stoeckli R, Bilz S, Kraenzlin M, Langer I, Keller U. Changes in bone mineral content after surgical treatment of morbid obesity. Metabolism. 2004;53:918-21.

21. Parrott J, Frank L, Rabena R, Craggs-Dino L, Isom KA, Greiman L. American Society for Metabolic and Bariatric Surgery Integrated Health Nutritional Guidelines for the surgical weight loss patient 2016 update: micronutrients. Surg Obes Relat Dis. 2017;13:727-41.

22. Busetto L, Dicker D, Azran C, Batterham RL, Farpour-Lambert $\mathrm{N}$, Fried $\mathrm{M}$, et al. Practical recommendations of the obesity management task force of the European Association for the Study of Obesity for the post-bariatric surgery medical management. Obes Facts. 2017;10:597-632.

23. Seyfried F, Lannoo M, Gsell W, Tremoleda JL, Bueter M, Olbers $\mathrm{T}$, et al. Roux-en-Y gastric bypass in mice-surgical technique and characterisation. Obesity surgery. 2012;22:1117-25.

24. Sherf Dagan S, Goldenshluger A, Globus I, Schweiger C, Kessler Y, Kowen Sandbank G, et al. Nutritional recommendations for adult bariatric surgery patients: clinical practice. Adv Nutr. 2017;8:382-94.

25. Lutz TA, Bueter M. The use of rat and mouse models in bariatric surgery experiments. Front Nutr. 2016;3:25.
26. Dubois V, Laurent MR, Jardi F, Antonio L, Lemaire K, Goyvaerts $\mathrm{L}$, et al. Androgen deficiency exacerbates high-fat diet-induced metabolic alterations in male mice. Endocrinology. 2016;157:648-65.

27. Bouxsein ML, Boyd SK, Christiansen BA, Guldberg RE, Jepsen $\mathrm{KJ}$, Müller R. Guidelines for assessment of bone microstructure in rodents using micro-computed tomography. J Bone Miner Res. 2010;25:1468-86.

28. Daci E, Verstuyf A, Moermans K, Bouillon R, Carmeliet G. Mice lacking the plasminogen activator inhibitor 1 are protected from trabecular bone loss induced by estrogen deficiency. J Bone Miner Res. 2000;15:1510-6.

29. Dempster DW, Compston JE, Drezner MK, Glorieux FH, Kanis JA, Malluche H, et al. Standardized nomenclature, symbols, and units for bone histomorphometry: a 2012 update of the report of the ASBMR Histomorphometry Nomenclature Committee. J Bone Miner Res. 2013;28:2-17.

30. Livak KJ, Schmittgen TD. Analysis of relative gene expression data using real-time quantitative PCR and the 2(-Delta Delta $\mathrm{C}(\mathrm{T})$ ) Method. Methods. 2001;25:402-8.

31. Sinnesael M, Laurent MR, Jardi F, Dubois V, Deboel L, Delisser P, et al. Androgens inhibit the osteogenic response to mechanical loading in adult male mice. Endocrinology. 2015; 156:1343-53.

32. Harris LA, Kayser BD, Cefalo C, Marini L, Watrous JD, Ding J. et al. Biliopancreatic diversion induces greater metabolic improvement than Roux-en-Y gastric bypass. Cell Metab. 2019;30:855-64.e3.

33. Cavin JB, Couvelard A, Lebtahi R, Ducroc R, Arapis K, Voitellier E. et al. Differences in alimentary glucose absorption and intestinal disposal of blood glucose after Roux-en-Y gastric bypass vs sleeve gastrectomy. Gastroenterology. 2016;150:454-64. e9.

34. Nguyen NQ, Debreceni TL, Bambrick JE, Chia B, Deane AM, Wittert $\mathrm{G}$, et al. Upregulation of intestinal glucose transporters after Roux-en-Y gastric bypass to prevent carbohydrate malabsorption. Obesity. 2014;22:2164-71.

35. Kellett GL. Alternative perspective on intestinal calcium absorption: proposed complementary actions of $\mathrm{Ca}(\mathrm{v}) 1.3$ and TRPV6. Nutr Rev. 2011;69:347-70.

36. Hood MM, Corsica J, Bradley L, Wilson R, Chirinos DA, Vivo A. Managing severe obesity: understanding and improving treatment adherence in bariatric surgery. J Behav Med. 2016;39:1092-103.

37. Galioto R, Gunstad J, Heinberg LJ, Spitznagel MB. Adherence and weight loss outcomes in bariatric surgery: does cognitive function play a role? Obes Surg. 2013;23:1703-10.

38. Gacs G, Barltrop D. Significance of Ca-soap formation for calcium absorption in the rat. Gut. 1977;18:64-8.

39. Corwin RL, Hartman TJ, Maczuga SA, Graubard BI. Dietary saturated fat intake is inversely associated with bone density in humans: analysis of NHANES III. J Nutr. 2006;136:159-65.

40. Kwon YM, Kim GW, Yim HW, Paek YJ, Lee KS. Association between dietary fat intake and bone mineral density in Korean adults: data from Korea National Health and Nutrition Examination Survey IV (2008-2009). Osteoporos Int. 2015;26:969-76. 